\title{
Rare coronary artery reactions after implantation of drug eluting stents
}

\author{
Tomislav Krčmar ${ }^{1 *}$, \\ Hrvoje Pintarić', \\ Nikola Pavlović', \\ Šime Manola', \\ Krešimir Štambuk², \\ Ivo Darko Gabrić', \\ Mislav Vrsalović ${ }^{1}$ \\ 'University Hospital Centre \\ "Sestre milosrdnice", \\ Zagreb, Croatia \\ ${ }^{2}$ Magdalena Clinic for \\ Cardiovascular Medicine, \\ Krapinske Toplice, Croatia
}

RECEIVED:

February 9, 2016

ACCEPTED:

February 20, 2016

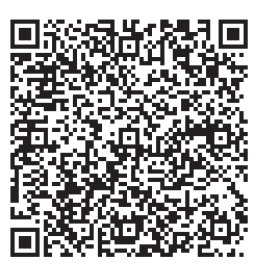

$\square$ Cardiologia Croatica 2016;11(3-4):110.
KEYWORDS: coronary artery stent fracture, coronary artery aneurysm, drug eluting stent, graft stent, coil. CITATION: Cardiol Croat. 2016;11(3-4):110. | DOI: http://dx.doi.org/10.15836/ccar2016.110

*ADDRESS FOR CORRESPONDENCE: Tomislav Krčmar, Klinički bolnički centar Sestre milosrdnice, Vinogradska 29, HR-10000 Zagreb, Croatia. / Phone: 385-99-520-0051 / E-mail: tomislav.krcmar@gmail.com

ORCID: Tomislav Krčmar, http://orcid.org/0000-0003-4689-1673 • Hrvoje Pintarić, http://orcid.org/0000-0002-7741-4194 Nikola Pavlović, http://orcid.org/0000-0001-9187-7681 • Šime Manola, http://orcid.org/0000-0001-6444-2674 Krešimir Štambuk, http://orcid.org/0000-0002-9107-6187 • Ivo Darko Gabrić, http://orcid.org/0000-0003-4719-4634 Mislav Vrsalović, http://orcid.org/0000-0002-8432-404X

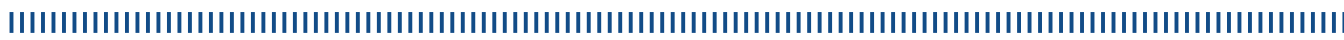

Coronary artery stent fractures are well known and more often described complications of percutaneous revascularisation ${ }^{1,2}$. Coronary artery aneurysms (CAA) after coronary intervention are rare, with a reported incidence of $0.3 \%$ to $6.0 \%$, and the most "aneurysms" are in fact pseudoaneurysms. Drugeluting stents (DES), which locally elute antiproliferative drugs, can dramatically inhibit neointimal growth, thereby suppressing restenosis, but at the same time potentially causing coronary aneurysms. In this presentation our goal is to discuss our already published case of stent fracture and one case of CAA after implantation of DES

First case is a 62-year-old female who was admitted for cardiac catheterization due to positive stress test consistent with anteroseptal ischemia. One year earlier she had undergone percutaneous coronary intervention (PCI) with placement of two sirolimus eluting stents to left anterior descent artery. Coronary angiography showing complete stent fracture in the mid-LAD with lateral dislocation of distal fragment, significant focal in-stent restenosis and saccular coronary aneurysm below the fracture level. We decided to place graft stent covering the site of the stent fracture and in-stent restenosis. After the procedure coronary artery aneurysm was completely excluded.

Second case is a 70-year-old female who had gone to PCI due to acute myocardial infarction of anterior wall. Everolimus eluting stent (EES) was implanted in LAD. Another EES was implanted in right coronary artery (RCA) due to suboclusion. Six months after patient was admitted because of reinfarction in anterior wall. Coronary angiography was performed showing two large CAA of LAD (bifurcation LAD/ first diagonal) and RCA at the site of previously implanted EES and thrombotic occlusion of LAD at the distal portion of EES. Intervention was performed with implantation of bare metal stent distally to EES in LAD. Patient is scheduled for next intervention with intention to exclude aneurysm of RCA with implantation of graft stent and coil embolization to LAD.

In conclusion coronary interventions are valid treatment options, but further investigation is necessary to determine natural history, and best therapies for DES-associated CAA and stent fractures.

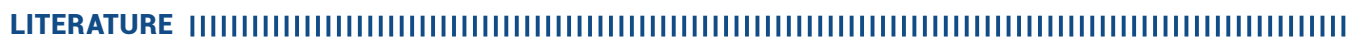

1. Stambuk K, Pavlović N, Gabrić ID, Krčmar T, Trbušić M, Manola S. Coronary artery stent fracture with in-stent restenosis and aneurysm formation: diagnosis and successful treatment with graft stent implantation. Int J Cardiol. 2011;148(2):253-5.

DOI: http://dx.doi.org/10.1016/j.ijcard.2010.04.087

2. Aoki J, Kirtane A, Leon MB, Dangas G. Coronary artery aneurysms after drug-eluting stent implantation. JACC Cardiovasc Interv. 2008;1(1):14-21. Dol: http://dx.doi.org/10.1016/j.jcin.2007.10.004 